\title{
Static load in the nursing profession; the silent killer?
}

\author{
Knibbe, J.J., N.E.Knibbe', \\ LOCOmotion, Research in Health Care, Brinkerpad 29, 6721 WJ Bennekom, The Netherlands.
}

\begin{abstract}
Traditionally back pain in the nursing profession is associated with heavy lifting of patients. Although there is a strong relationship between heavy loads on the spine and lifting patients, literature indicates that there is a major factor that should not be underestimated: static load. Static load can be defined as the result of static, not moving, not dynamic, working positions. For example when a caregiver is washing a patient on a bed which is too low, her back is in a static (bended) stooped position up to several minutes. Exposure to static load is an underestimated silent killer of nurses musculoskeletal system . There is evidence from this cross-sectional study that static load can be reduced by a combination of introducing the right equipment, creating awareness and education.
\end{abstract}

Keywords: ergonomic, health care, back pain

\section{Introduction}

Traditionally back pain in the nursing profession is associated with heavy lifting of patients. Although there is a strong relationship between heavy loads on the spine and lifting patients, literature indicates that there is a major factor that should not be underestimated: static load. In spite of all sorts of efforts across the world, occupational back pain among nurses leads to high costs for health care facilities and personal suffering for nurses and ergonomic solutions remain necessary [3-7]. Therefore it is important to look at possibly underestimated sources of physical load.

\section{Method}

\subsection{Static load}

Static load can be defined as the result of static, not moving, not dynamic, working positions. For example when a caregiver is washing a patient on a bed which is too low, her back is in a static (bended) stooped position up to several minutes. Some researchers refer to this kind of physical load as 'covert load' as the load is not visible. Static load can be strenuous for two reasons. First of all the weight of the caregivers own trunk, arms and head places a strain on the back, neck and shoulder area. These parts of the body make up about two thirds of one's total body weight. The more the caregiver bends forward, the greater these loads become. Secondly the muscles in the area's mentioned must stabilize the trunk, head and arms. This requires a great deal of muscle power, which rapidly increases the more the caregiver bends forward. If the posture must be maintained for any length of time, muscle fatigue and pain can occur quickly.

\subsection{Static load in research: the impact of a silent killer}

Still the majority of back pain prevention programs around the globe focus on lifting and handling of patients. The question can be raised why still so little attention in back pain preventions programs is paid to

* Corresponding author. E-mail: j.j.knibbe@planet.nl.

${ }^{11}$ LOCOmotion, n.e.knibbe@,planet.nl,

$1051-9815 / 12 / \$ 27.50$ (C) 2012 - IOS Press and the authors. All rights reserved 
static load. Even Florence Nightingale wrote in one of her books that 'The nurse should have easy access to both sides of the bed and should be able reach any part of the patient without having to bend over'. This was in 1859. In daily nursing practice nowadays this so-called 'silent killer' still lies in waiting during static load tasks like washing, showering and bathing.

As stated above there is not much attention for static load in working condition programs in the literature. Engels et al. studied the effects of an ergonomic educational course on postural load, perceived physical exertion and biomechanical errors. The trainees showed a significant improvement in the number and percentage of harmful postures and biomechanical errors, whereas the controls did not.

\section{Results}

An in depth static load reduction program was evaluated by Knibbe and Brinkhoff $[1,7]$. The program consisted of a one-day training program on reducing static load for all caregivers, weekly reminders to create awareness, a survey among all caregivers, presentation of the results of this survey, questions were asked during group sessions to encourage caregivers to think about problem tasks and solutions regarding static load, individual support from ErgoCoaches, an information booklet with basic information about static load, a 30-minute e-learning module, use of ergonomic aids such as the multipurpose shower chair, a two-hour training session on the use of this chair and a number of height-adjustable stools for use in patients' rooms. The results were positive. Before the ErgoStat programme the percentage of working hours spent in static overloaded position was 34. After the ErgoStat program it dropped to $25 \%$. During showering and washing it dropped from $54 \%$ to $25 \%$.

\section{Guidelines}

In order to reduce the static load, and by doing so potentially gaining time and improving quality of care, clear guidelines are required. In The Netherlands guidelines are implemented and reinforced by the Dutch labor inspectorate [6,7]. Also an ISO standard 11226 is available stating that trunk flexion between $0^{\circ}$ and $20^{\circ}$ is acceptable and more than $60^{\circ}$ is not acceptable.

\section{Conclusions}

Exposure to static load is an underestimated silent killer of nurses musculoskeletal system . There is evidence that it can be reduced by a combination of introducing the right equipment, creating awareness and education.

\section{References}

[1] Brinkhoff A, Knibbe NE. The ErgoStat Program Pilot study of an ergonomic intervention to reduce static loads for caregivers. Professional Safety, May 32-39 2003.

[2] Engels et al., Physical Workload and Its Assessment Among the Nursing Staff in Nursing Homes. Journal of Occupational Medicine, 36, 3, 338-345 (1994).

[3] Hignett, S. Postural analysis of nursing work. Applied. Ergonomics. Vol 27, No. 3. pp. 171-176, 1996.

[4] Hignett, S., Crumpton, E., Ruszala, S., Alexander, P., Fray, M., Fletcher, B. (2003). Evidence based patient handling: systematic review. Nursing Standard, 17 (33), 33-36.

[5] Jansen, J., Morgenstern H., Burdorf, A. (2004). Dose-response relations between occupational exposures to physical and psychosocial factors and the risk of low back pain. Occupational Environmental Medicine, 61(12): 972-979.

[6] Knibbe, J.J., Friele, R.D. (1999). The use of logs to assess exposure to manual handling of patients, illustrated in an intervention study in home care nursing. International Journal of Industrial Ergonomics 4 (24), 445-454.

[7] Knibbe, J.J., Knibbe, N.E., Geuze, L. (2008). Een hap uit een gegroeide olifant, vierde nationale monitoring fysieke belasting, SOV\&V, Den Haag (in Dutch). Fourth National Monitoring, Unions \& Employers organizations, The Hague.

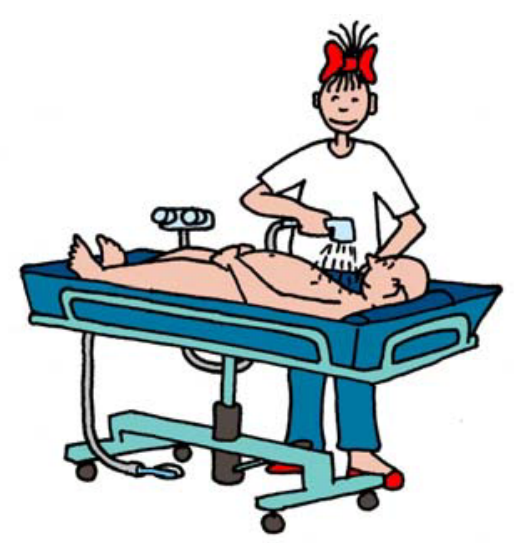

